\title{
Information Literacy and Open Science: Before and After the New ACRL Framework*
}

\author{
Carlos Lopes ${ }^{1^{*}}$, Maria da Luz Antunes ${ }^{2}$, and Tatiana Sanches ${ }^{3}$ \\ ISPA - Instituto Universitário, Lisboa, Portugal \\ clopeseispa.pt \\ ${ }^{2}$ Escola Superior de Tecnologia da Saúde de Lisboa, Instituto Politécnico de \\ Lisboa, Lisboa, Portugal \\ mluz.antunesdestesl.ipl.pt \\ ${ }^{3}$ Instituto de Educação, Universidade de Lisboa, Lisboa, Portugal \\ tsanchesefpie.ulisboa.pt
}

\begin{abstract}
In 2000, ACRL published the Information Literacy Standards, clarifying and describing specific learning objectives for higher education students. The document recognized the role of librarians who had long been informally developing these practices. But the Standards have evolved and adapted. In 2016, the ACRL adopted the new Framework, which sustains a metamorphosis. Information literacy remains a pattern of integrated competencies that encompass the reflexive discovery of information, the understanding of how information is produced and valued, and the use of information in the ethical and legal creation of new knowledge. Aim of the study: Based on a literature review, this study discusses the challenges and practical implications that the new Framework has in Open Science, its flexibility, the relevance for the privacy and rightful author of scientific data, and the new steps of the academic libraries to be involved as key players for the Open Science contents.
\end{abstract}

Keywords: Information literacy, open science, open access, ACRL framework, higher education.

\section{Introduction}

In 2000, the Association of College and Research Libraries [1] published a document that standardized and described the specific learning objectives for higher education students in the area of information (i.e. what and where to research, how to define search

\footnotetext{
* The final authenticathed version is available online at https://doi.org/10.1007/978$\underline{3-030-13472-3 \quad 23}$

* The three authors are members of the Applied Psychology Research Center Capabilities \& Inclusion (APPsyCI), Lisboa, Portugal.
} 
strategies, how to select and evaluate retrieved information, how to use the information in an ethical and legal way) - Information literacy competency standards for higher education. These Standards have established learning objectives to actively implement information literacy (IL) in the academic community. They also recognized the role of information professionals who had long been informally developing these practices. Over the years, many disciplines have been inspired by the Standards to formulate their specific objectives in the teaching-learning process, namely in nursing, psychology and health sciences. But the Standards had to evolve and adapt. As the disciplines regularly evaluated and accredited their practices and curricula, the practice of IL also had to be reviewed and re-evaluated in terms of its relevance and application. In January 2016, after two years of elaboration and incorporation of extensive comments from information professionals, ACRL adopted the Framework for information literacy for higher education [2].

How does the new Framework articulate with Open Science? How can academic libraries maximize IL skills with the benefits of Open Science? Th main purpose of the study discusses the challenges and practical implications that the new Framework has in Open Science, its flexibility, the relevance for the privacy, the copyright of scientific data, and the new steps of the academic libraries to be involved as key players for the Open Science contents.

The new Framework renews the concept of IL as: “... the set of integrated abilities encompassing the reflective discovery of information, the understanding of how information is produced and valued, and the use of information in creating new knowledge and participating ethically in communities of learning" [2, p.2].

This new document also opens the way for information professionals, teachers and other institutional partners; to reformulate contents, training courses, curricula and credits to be awarded [3]; to link IL to successful student initiatives [4]; to collaborate in the pedagogical research and to involve the students themselves; and to develop and broaden the discussion about the teaching-learning process.

\section{From the Standards to the New Framework: the Changing Process}

The new Framework supports an expected metamorphosis given the need to align the existing Standards with the current information use and creation process. But the process of adopting the new Framework has been controversial. While some recommend the new document for its flexibility [5], others criticize it and call it elitist [6]. One of the main criticisms was that this was just a new document, rather than a review of the document they were waiting for [7]. Regardless, the shift in Standards from IL has brought renewed energy and a new level of discussion around the training provided by academic information professionals.

For years, the Standards have offered to information professionals a tool to plan, evaluate and communicate the need to integrate IL skills into academic curricula [3]. At five levels, each of which comprised a subset of performance indicators along with the 
results of the evaluation, the Standards recognized the different levels of competencies in the process of locating, accessing, evaluating, and using the information [1].

What are the major changes of the Framework compared to the Standards of IL? The main difference is a change in behaviour against a more philosophical theory of the threshold concepts. While the Standards outlined specific task-based learning objectives (e.g. "access the needed information effectively and efficiently" and "evaluate information and its sources critically") [1, p.2-3], the new Framework presents a set of interconnected frames or main concepts, representing broad ideas that are intended to be applicable to many academic disciplines [2] [8-9]: Authority is Constructed and Contextual; Information Creation as a Process; Information has Value; Research as Inquiry; Scholarship as Conversation; Searching as Strategic Exploration.

Each of these frames includes a knowledge practice section used to demonstrate how the domain of the concept leads to its application in new situations and to the creation of more knowledge; it also includes a set of provisions that work the know-how in the learning process.

The knowledge practices in each frame comprise a non-exhaustive list of behaviours that highlight the involvement of an individual with IL competencies in the academic community [9]. The dispositions in the teaching-learning process embody students' preferences and attitudes about how they learn. Each frame is intended to involve information professionals in the exploration of an original concept underlying IL, which will ideally enable students to understand latent concepts in information, beyond the mere mechanics of locating, using, and citing information [7-8].

On the other hand, the threshold concepts are ideas that can be found in any discipline and that constitute a framework that guarantees their expanded understanding, but also ways of thinking and exercising within the same discipline. Schaub and McClure emphasize the concepts' threshold, "focused on the whys of information instead of the hows" [7, p.2].

Thus, the focus is on why the reason for the information and not on how to use the information. The approach of the threshold concepts in the teaching-learning process must therefore be centered on the student. The concepts require that information professionals remain aware of the knowledge they give with certainty and never assume that others have the same understanding of an idea [9]. The idea of knowledge, which a student may find strange, confusing, difficult or contrary to a prior understanding, requires information professionals, as trainers, to deepen this difficulty. It requires information professionals to abandon their expertise and meet the student - wherever he / she is. In the same way, they are asked to be interesting information professionals to build a pedagogical approach based on skills [7]. The threshold concepts are a useful way to think about the contents of the courses, to define the relationship between teachers, students and learning outcomes.

The assessment of behaviour in IL has also changed. While the Standards defined a list of twenty-two measurable performance indicators in IL, the new Framework moves away from any set of skills and encourages information professionals to develop their own needs.

The discussion about the Standards of IL is relevant to academic information professionals. For specialized librarians who work with a specific field it is even more 
important because they are confined to following the discipline's specific accreditation standards and their learning objectives. Generally, they provide training in the framework of evidence-based practice rather than strictly based on IL. Although both can be comparable [10], the truth is that these specialized librarians responsible for training do not consult ACRL's resources regularly for framing their training practices [11] - since December 2016, the ACRL has made available, among other things, a sandbox (http://sandbox.acrl.org/), which is an open access repository that houses materials constructed and shared by librarians and other information professionals to integrate the ideas of the new Framework into the training provided by them. The new Framework can influence the librarians' training, as its vision points to knowledge-based research concepts (rather than the competencies outlined in the Standards) and addresses the information needs of researchers at a higher level, while its conceptual flexibility allows librarians to approach learning at all levels of academic development [11].

\section{Challenges for Open Science}

The new Framework suggests a different approach in order to integrate IL training in Open Science, highlighting the importance of acquiring specific skills. The new Framework is also more flexible than the previous Standards. With the diverse approaches of Open Science in training, often blending scientific research with practicebased experiences, this flexibility has significant advantages [11]. Provided and competency-based training has a temporary value for the student, but the threshold concepts of the new Framework ensure, as a final result, a broader and more adaptable understanding of the nature of information and better lifelong learning: "This framework highlights the concept of metaliteracy that suggests a new vision of IL as an overarching set of abilities where students are consumers and creators of information who can take part in collaborative spaces. Metaliteracy demands behavioural, affective, cognitive, and metacognitive engagement with the information ecosystem" [12, p.2].

Some authors have shown in recent studies that the academic community has a positive attitude towards cooperation with information professionals and that they are available to take responsibility for organizing editorial processes to ensure the quality control of scientific publications [4], [13]. From the publishers' point of view, the new model of academic communication will deliver more benefits than the traditional publishing model: free access for readers (e.g. through library sites); the inexpensive platform for the publications (even if libraries have to secure costs) and convenient management (through collaboration with other libraries). And this whole process can be achieved through the creation of institutional data repositories by information professionals in collaboration with academic researchers [14]: "Open Science is the practice of science in such a way that others can collaborate and contribute, where research data, lab notes and other research processes are freely available, under terms that enable reuse, redistribution and reproduction of the research and its underlying data and methods" [3, p.12]. 
Open Science involves, in essence, two fundamental dimensions: a) the opening and sharing of research results from publications to research data; b) the openness in the research methods and tools themselves, making processes open and collaborative from the outset and seeking, where appropriate, the involvement of other actors, in addition to the scientific community, in the collection and analysis of research data, in what is designated Citizen Science. Open Science presents benefits and advantages to science and to society, given the opening of research processes and the speed of dissemination of results in conditions that can be reused not only by the scientific community but also by society as a whole. Open Science is thus transparent and accessible and knowledge is shared and developed through collaborative networks. Open Science is based on principles such as rigor, responsibility, reproducibility, but also inclusion, fairness, equity and sharing in research [3]. Ultimately, it seeks to change the way research is done, who is involved, and how it is valued.

\section{$4 \quad$ Articulation of the New Framework with Open Science}

The analysis of training courses developed in an academic context points to a relationship between IL and the concepts associated with Open Science.

Open Science represents the link between the academic and research environment with a broader public, the transparency of research processes and open access to scientific data and publications. Open Science follows the presuppositions of making research and its data accessible to society as a whole; its concept is associated with the definition of science, described as the retrieval, analysis, publication, critique and reuse of data [15]. The concept of Open Science is thus associated with that of IL, adding the philosophy of the trinomial: Search - Organize - Publish [16].

Generally, researchers manage their research and have competencies in information search strategies, evaluation of research results, creation of alerts, management of references and publication of results [17]. Open Science requires new skills in the management of scientific data, open sources and open access publishing. It is in this understanding that Open Science intersects with IL. Open Science is, therefore, the source and result of scientific research, teaching and learning in an academic context, so that higher education institutions fulfill their mission through Open Science. In this context, higher education libraries contribute to the access of Open Science through IL, that is, the promotion of practices that involve knowing how to research, select, evaluate and use information. They are skills that contribute to the improvement of student performance and benefit the work of researchers [16].

The concept of Open Science has already been appropriated by researchers and is particularly used in the promotion of scientific results for a greater, open public access [4]. Other features include participation, collaboration, peer networking and information sharing. Other concepts were also identified in Open Science, such as policies, evaluation of results, access to data and scientific publications. Awareness of researchers' social networks has been noted, including the trend of alternative metrics. The big differences emerged from domain-specific research objects, methodologies, 
and procedures in data acquisition and management. The culture of each scientific discipline leads to differences in information behaviour, as it is reflected in the formats of publication, communication and use of information [17]. At the same time it gives a sense of responsibility, reliability and reproducibility to science, inhibiting or exposing errors, bad practices or even scientific fraud. Transparency in Open Science also makes it responsive to societal challenges and facilitates innovation and the appropriation of new knowledge for the development of new products and services, that is maximizing the economic and social return of public investment in research and in science [18].

In a social, technological and communal dimension, the concept of Open Science requires a new conceptualization of the concept of IL in research. Below we analying the new conceptual frames:

\subsection{Authority is Constructed and Contextual}

Questioning authority has been a mantra for everyone, from Copernicus to neo-punks, and it seems that the idea is about to be codified as a territory belonging to the library. Understanding this concept allows students to critically examine what the evidence is considered to be. Whether it is a Wikipedia article or a peer-reviewed conference paper, it is important for the student to ask relevant questions about the origin, context, and appropriateness of their current information needs. This frame emphasizes the idea that all sources of information have a purpose and a context, and some are more helpful than others, depending on the information need.

The knowledge practices of this frame include the identification of the authority indicators when associated with the information, the understanding that many areas of knowledge recognize authorities (e.g. official, credited, certified), and the recognition that these contents can be presented in a formal or informal format. Some learning objectives include: students will be able to recognize appropriate information resources by discipline; recognize that an author can be seen as an authority in a specific area and recognize his/her responsibility; distinguish between academic and popular sources; to learn how to distinguish a story from an editorial article; and to express the desire to find better resources to improve quality.

The dispositions on authority refer to the need to keep an open mind, to be aware of the importance of critically evaluating content and to recognize that there are necessarily problems in the face of traditional notions of belonging and authority [2].

In higher education and in Open Science the ability of each student to be an information consumer and potentially an information producer is notorious. Thus, clearly disclosing the source of funding and submitting declarations of conflicts of interest when submitting papers in scientific publications and public presentations is considered good practice. Who funds research? What is not disclosed? Why is it not disclosed?

\subsection{Information Creation as a Process}


Format is how tangible knowledge is disseminated, so its essential feature comes down to the whole underlying process of creating, producing, and disseminating information rather than how content is disseminated [2]. This is probably the way ACRL recognizes that non-traditional publishing formats are as relevant as traditional ones. It is not important how the content is published because, regardless of the form of information, the expert will always look for the process underlying the creation as well as the final product in order to critically evaluate this information and use it as evidence.

Knowledge practices include: the evaluation between the process of creating information and the specific need for information; the articulation of the traditional processes with the most recent ones of creation and dissemination of the information in a certain discipline; the understanding that, regardless of its format and the method of access, the information can be understood differently; the articulation of the characteristics and purposes of the various formats; and identifying which formats best meet specific information needs [2].

Evaluating the format of a publication as to its credibility and quality is one of the researchers' concerns. Identifying the impact of the process of creating information in relation to the need for information is a question that can be answered in the current Open Science ecosystem because researchers are able to evaluate information with defined criteria, articulate the purposes of various types of information, and distinguish between format and access method.

\subsection{Information Has Value}

This concept directly addresses Open Science, open source, open access, copyright and publisher rights, and intellectual property. If the growth of the information age has taught us anything, it is that information is a product. This frame recognizes that the creation of information and all products derived from information require a commitment of time, original thinking and resources that need to be respected by those who seek to use these products, but also by those who want to create their own work on the basis of the work of others [2].

Knowledge practices and some learning objectives: students should have the notion of plagiarism; cite the source correctly and understand the reason for doing so; distinguish between plagiarism and copyright infringement; identify academic publishing practices; be available to invest their own resources to keep up to date; determine the potential use of a copyrighted image, and explain the value of citation sources.

The pillars of this frame are present in the genesis of Open Science and integrate the concerns of researchers: information can be bought and sold; information can be affected by economic, political and sociological forces; and finally, information that seems to be free may have to be paid when shared on a website, for example. In fact, the information has VALUE ... but someone will have to pay for it. In Open Science it is imperative to cite the source and respect the authors' original ideas. 


\subsection{Research as Inquiry}

This frame could be designated as 'The Scientific Method'. At bottom, it is understood that research is interactive and depends on increasingly complex questions whose answers develop new questions or lines of research in any area of knowledge [2]. This frame does not define student learning outcomes or prescribe teaching methods. But it invites its use for the contextualization of IL practices.

Knowledge practices and some learning objectives: students will know who to turn to for a library survey; locate a resource in the catalog; locate appropriate information resources by discipline; formulate research questions based on available data and information gaps; apply research methods appropriate to the need, context and type of consultation; identify key concepts and related terms in order to locate relevant sources.

Dispositions for this frame include: assessment of persistence, adaptability and flexibility, critical thinking practice, and the recognition that learning and discovery are an error-based process [2].

Relevant to Open Science is the inclusion of lifelong learning as a practice of knowledge, which is a competence consistently referred to as a behavioral goal for psychologists, educators, and other social science professionals. Open Science demonstrates that research is an interactive process, which requires a lifelong learning, trying to determine what questions can be answered in science, how can information gaps and available scientific data help in the research process, and the impact of effective and comprehensive communication in informed and self-directed learning, in a process of recognition that learning and discovery are processes based on errors.

\subsection{Scholarship as Conversation}

This frame confers on the production of academic results the idea that it is a commitment to the community [2], that is, that the academy is permanently involved in new contributions and discoveries, giving the academic environment a space of dialogue where ideas are formulated, debated and argued.

Some examples of knowledge practices for this frame include: identifying the contribution that articles, books, and other academic products bring to the enrichment of contents of knowledge areas; and the contributions of academic and scientific communication [2]. In higher education, it is relevant to understand that it is from what others said and did before that the possibility of new scientific knowledge arises; hence the need for citation and referral as a form of dialogue with peers [19].

Some learning objectives: students should be able to analyze the bibliography, footnotes, and references to locate additional information sources; recognize and describe the purpose of the research; identify the contribution of academic work to science; contribute to academic dialogue as a creator / critic; understand the chain of citations to evaluate the impact of a scientific work; understand and analyze a peerreviewed academic article and identify and understand all parts of the article.

Open Science can foster a reform of the academic evaluation system, encouraging researchers to change their publishing and dissemination practices, leading to cost 
reductions and the valuation of academic content to the detriment of quantity and impact factors. In Open Science, this frame is a platform for dialogue. Dispositions include the recognition that academic communication takes place in several levels, the valorization of the content emanating from the user and the understanding that the responsibility of academic creation is associated with the contributions of other channels and other types of participation in science [2].

\subsection{Searching as Strategic Exploration}

With this frame information professionals finally return to what is most important as trainers in the library: teaching students to identify, locate, retrieve and use information sources. Finding the information requires a combination of research, discovery and some luck - there is not an equal recipe for everyone!

Some knowledge practices include: determining the scope of the question; identifying sources; constructing research strategies; and using citation managers. In turn, the dispositions include: persistence, adaptability and flexibility, recognition of the value of navigation and methods of retrieval of information, understanding that the first attempts in research do not always result and also the recognition that 'enough is enough' in information retrieval [2].

Some learning objectives: students should be able to locate metadata in a catalog; identify keywords from a particular topic; implement searches in a database and on the internet and recognize the difference between them; identify keywords and synonyms and build a search strategy with appropriate operations in different interfaces; determine if the information retrieved meets their needs and refine the search, if necessary; reflect on the utility of making mistakes in the research process; divide the search into fundamental concepts and discuss additional steps for each concept.

\section{The Framework and Its Practical Implications for Open Science}

From a systemic perspective, science can be characterized as an organized, cumulative and structured system of processes, as an open and non-isolated system purposely created to produce knowledge, which depends on scientific information and is prepared for sharing information with the surrounding community. Based on the objective of the present theoretical reflection, and given the contributions of IL, in an academic context, it is possible to identify some challenges to explore in Open Science: a) IL as a variable dependent on the modus operandi of the scientific process; b) IL in the academic context as a dimension of the process of scientific information; c) different channels of circulation and dissemination of knowledge; d) public participation in science to be considered in the strategies of IL in an academic context; e) need to understand issues associated with data management and curation. 


\section{Conclusions}

Higher education is complex, demanding and challenging. Students play an important role in creating new knowledge, understanding the contours and dynamic changes of the information ecosystem, as well as in the ethical and legal use of scientific information and data. Information professionals, in turn, are responsible for a new role in the teaching-learning process and contribute to student learning. They are the great enablers of the creation of a new curriculum, oriented to the competences of IL in collaboration with the teachers. As IL programs continue to be developed, implemented, reflected upon and reviewed both in libraries (informal learning) and integrated in academic curricula (formal learning), the Framework is a reference document in which information professionals and teachers find inspiration and support. It is useful for the development of knowledge infrastructures, including systems and services that actively support researchers in their contact with information, communication and collaboration.

The present theoretical reflection showed the importance of recognizing the key areas around Open Science, trying to ensure that IL, as a learning tool, corresponds to its objectives. In this context, academic libraries need to create a more effective involvement in advocacy. It is also essential to encourage researchers and all interested parties in the process of scientific research, and even those who show some skepticism about Open Science, to associate with the movement. The active partnership between researchers, information professionals, librarians, science managers, institutions and agencies is recommended. The need for information professionals to reformulate and invest in their skills, in data management and, why not, in their creativity, is also emphasized.

\section{References}

1. IL Competency Standards for Higher Education, www.ala.org/ala/mgrps/divs/acrl/standards/standards.pdf

2. Framework for IL for Higher Education, www.ala.org/acrl/standards/ilframework

3. FOSTER.: The Open Science Training Handbook. European Commission, Brussels (2018)

4. Corrall, S.: Designing Library for Research Collaboration in a Network World: an Exploratory Study. Liber Q. 24, 17-48 (2014)

5. Jacobson, T. E., Gibson, C.: First Thoughts on Implementing the Framework for Information Literacy. Comm. Inf. Lit. 9, 102-110 (2015)

6. Bombaro, C.: The Framework is Elitist. Ref. Serv. Rev. 44, 552-563 (2016)

7. Schaub, G., McClure, H.: Information Literacy Threshold Concepts and the Association of College and Research Libraries' Framework for IL for Higher Education. O-bib. 4(1), 1-9 (2017)

8. Fisher, Z.: Facing the Frames: Using the Framework as a Guide for a Credit-Bearing IL Course. C\&RL News 78, 354-355 (2017)

9. Swanson, T.: Sharing the ACRL Framework with Faculty: Opening Campus Conversations. C\&RL News 78, 12-48 (2017)

10. Adams, N.: A Comparison of Evidence-Based Practice and the ACRL Information Literacy Standards: Implications for Information Literacy Practice. Coll. Res. Libr. 75, 232-248 (2014) 
11. Schulte, S. J., Knapp, M.: Awareness, Adoption, and Application of the Association of College \& Research Libraries (ACRL) Framework for Information Literacy in Health Sciences Libraries. J. Med. Libr. Assoc. 105, 347-354 (2017)

12. Aharony, N., Gur, H.: The Relationships Between Personality, Perceptual, Cognitive and Technological Variables and Students' Level of Information Literacy. J. Librariansh. Inf. Sci. November 29, (2017)

13. Jaguszewski, J. M., Williams, K.: New Roles for New Times: Transforming Liaison Roles in Research Libraries. Association of Research Libraries, Washington (2013)

14. Ogungbeni, J. I., Obiamalu, A. R., Ssemambo, S., Bazibu, C. M.: The Roles of Academic Libraries in Propagating Open Science: a Qualitative Literature Review. Inf. Dev. 24, 113 121 (2018)

15. Sobre Ciência Aberta, http://www.ciencia-aberta.pt/sobre-cienciaaberta

16. Antunes, M. L., Lopes, C., Sanches, T., Rodrigues, B. S.: Literacia da Informação: o Primeiro Degrau Para a Ciência Aberta. In: VIII Encontro Ibérico EDICIC 2017, pp. 47-56. Faculdade de Letras da Universidade de Coimbra, Coimbra (2017)

17. Alonso-Arévalo, J., Lopes, C., Antunes, M. L.: Literacia da Informação: da Identidade Digital à Visibilidade Científica. In: Lopes, C., Sanches, T., Andrade, I., Antunes, M. L., AlonsoArévalo, J. (eds.) Literacia da Informação em Contexto Universitário, pp. 59-85. ISPA, Lisboa (2016)

18. Steinerová, J.: Open Science and the Research Information Literacy Framework. In: $4^{\text {th }}$ ECIL 2016, Information Literacy: Key to an Inclusive Society, pp. 277-285. Springer, London (2016)

19. Shields, K., Cugliari, C.: Scholarship as Conversation: Introducing Students to Research in Nonprofit Studies. C\&RL News 78, 137-140 (2017) 